\title{
Strengthening human autonomy in the era of autonomous technology.
}

\author{
Contemporary perspectives on interaction with 'autonomous things'
}

\author{
TONE BRATTETEIG \\ Department of Informatics, University of Oslo \\ REBEKKA SOMA \\ Department of Informatics, University of Oslo
}

\author{
DIANA SAPLACAN \\ Department of Informatics, University of Oslo \\ JOHANNE SVANES OSKARSEN \\ Department of Informatics, University of Oslo
}

\begin{abstract}
The aim of this workshop is to address the role that human autonomy presently receives in HCI research and how "autonomous technologies" might challenge, rather than facilitate human autonomy. We acknowledge a need for new ways of understanding HCI and interaction design as digital technologies develop in the "4th wave". In this workshop, participants are invited to a discussion where the autonomous human-being-who can act autonomously with autonomous technologies-is emphasized, beyond simple human control to a more flexible, sophisticated, subtle, and sustainable autonomy.
\end{abstract}

\section{CCS CONCEPTS}

- Human-centered computing; • Human-computer interaction; $\bullet$ HCI theory, concepts, and models;

\section{KEYWORDS}

human autonomy, autonomous technology, design implications

\section{ACM Reference Format:}

TONE BRATTETEIG, DIANA SAPLACAN, REBEKKA SOMA, and JOHANNE SVANES OSKARSEN. 2020. Strengthening human autonomy in the era of autonomous technology.: Contemporary perspectives on interaction with 'autonomous things'. In Proceedings of the 11th Nordic Conference on Human-Computer Interaction: Shaping Experiences, Shaping Society (NordiCHI '20), October 25-29, 2020, Tallinn, Estonia. ACM, New York, NY, USA, 3 pages. https://doi.org/10.1145/3419249.3420097

\section{INTRODUCTION}

We know that technological development often opens new areas of application. The latest technological advancements in AI and ML open up for increasing the range of application areas (i.e., areas for automation) as well as the levels of automation. HCI-researchers have referred to socio-technical shifts as paradigm shifts [1] or waves [2-5], emphasizing that the waves coexist like generative metaphors [6]. The previous three waves: (1) human factors and ergonomics, (2) symbolic information processing, and (3) networks and mobile computing, consumer technologies, human experience,

Permission to make digital or hard copies of part or all of this work for personal or classroom use is granted without fee provided that copies are not made or distributed for profit or commercial advantage and that copies bear this notice and the full citation on the first page. Copyrights for third-party components of this work must be honored.

For all other uses, contact the owner/author(s).

NordiCHI '20, October 25-29, 2020, Tallinn, Estonia

(c) 2020 Copyright held by the owner/author(s).

ACM ISBN 978-1-4503-7579-5/20/10.

https://doi.org/10.1145/3419249.3420097 and user participation have been accompanied by a change in the theoretical basis for understanding interaction from psychology via cognitive science to a wider range of disciplines including philosophy (e.g., phenomenology [7]), social sciences (e.g., situated action $[8,9])$ and design $[10,11]$. Current discussions of the future development of HCI include human-computer entanglement [12] and integration $[13,14]$ the computer as a partner [15], and political positioning [16-18]. We are particularly interested in discussing the challenges to HCI by a set of relatively new technical possibilities: autonomous technologies.

In an already complex and cluttered environment, the combination of these three waves has further complicated our environment as it becomes populated with physical and virtual systems. Now, more than ever, digital systems and artifacts get more entangled with almost all aspects of societal life, and autonomous (and ubiquitous) technologies add to the number of things we interact with in our daily lives: the digital permeates society. Autonomous technologies appear as self-directed and/or self-sufficient [19]: they do their things without explicit instructions from a human. Digital artifacts or systems that are "artificially intelligent" (AI) or use "machine learning" (ML) and neural networks to make decisions often operate outside the reach of human interventions; they are imperceptible as we cannot always know what they do or why they do it. In the light of the new kinds of interactions offered by the latest technological advancements, this workshop particularly addresses human autonomy, focusing on the individual humans and their autonomy and self-determination as the overall goal for HCI. How can we, as researchers and interaction designers, understand, evaluate, and describe human-technology interactions in an increasingly complex and technologically diverse environment? The aim of this workshop is to address the role that human autonomy presently receives in HCI research, and how we can ensure that this perspective gets proper attention as autonomous technology advances beyond (the average) human understanding.

\section{THEMES FOR THE WORKSHOP}

With our main interest being 'autonomous technologies' and how they might make the interaction imperceptible, challenging rather than facilitating human autonomy as a background, this workshop focuses on the role of human autonomy and the right of the individual to govern their own lives. We want to explore interaction goals, relevant theories, methods, relations between the human and the computer, and relevant values and questions for these technologies, potentially defining a shift in HCI. We are particularly interested in 
discussing the following themes but are also open for other takes on our main questions.

\subsection{Imperceptible interactions}

Interactions that we cannot directly perceive (see, touch, feel) or understand (the mechanisms behind the technology is hidden) such as; smart environments and homes, ML algorithms and predictive technologies, robot "decisions". How do people (users and designers) relate to and understand autonomous technology when they cannot sense or make sense of its operations (see e.g., [20])? How can we design for human autonomy when the human does not know $\mathrm{s} /$ he interacts or what the autonomous technology does? How do we describe and critically consider being an involuntary user of autonomous (and ubiquitous) technology? How can humans relate to autonomous and/or imperceptible 'things' - or how do we describe the human-thing and subject-object relations?

\subsection{Interaction with autonomous things}

Interaction with robots, (chat)bots, or smart vehicles. We have seen that with the introduction of a robot in a domestic setting, humans need to carry out facilitation [21,22] or articulation work [23-25]. How do we describe how we relate to technology that performs tasks for us and with us? How do people handle having autonomous or automatic things as "colleagues" or "partners" in work where work tasks are distributed or shared by humans and technology? How do people whose workflow includes AI/ML-based decisions relate to the automatic decision-making process? What is a good mix or fit between machine and human decision-making?

\subsection{Perspectives on "imperceptible interactions with autonomous things"}

We welcome philosophical and theoretical perspectives on human autonomy in today's society and how technology can strengthen human autonomy. How do we describe and critically evaluate the different ways that technology represent, protect, and support or weaken human autonomy? Within this theme, we include questions about how we can design these interactions, i.e., how to design for capabilities [26], prolonged mastery [27], or situated abilities $[28,29]$, how to design for perception and meaning-making when imperceptible interaction is the basis, how to design for interaction with moving things like robots [23, 24, 29, 30] or autonomous vehicles? We also think that a debate about the (human) values and foci of the 4th shift in interaction design / HCI is timely, as are possible mechanisms and design concepts for increasing human autonomy [31].

We wish to further explore interaction goals, relevant theories, methods, relations between the human and the computer, and relevant values and questions for these technologies, potentially defining a shift in HCI.

\section{OUTCOME}

With human autonomy as our primary perspective, we invite participants in this workshop to discuss how recent technological developments change the core of $\mathrm{HCI}$, and how we want to envision this field as it moves forward: how to design, evaluate and implement interactive systems that enable people to govern their own lives. By emphasizing the importance of human autonomy in a technology-driven society, the challenges we as a community face will become clearer, and thus possible to address and tackle. Presently, the challenge of preserving human autonomy during the next socio-technical wave has not been addressed in the NordiCHI community. Further, such perspectives are much needed if HCI should renew itself and its theoretical basis, while simultaneously maintaining our Scandinavian tradition and Nordic values.

\section{REFERENCES}

[1] Harrison, Phoebe Sengers, and Deborah Tatar. 2007. The Three Paradigms of HCI. Proc. of Alt.Chi, ACM.

[2] Susanne Bødker, 2006. When second wave $\mathrm{HCI}$ meets third wave challenges. Proceedings of the 4th Nordic conference on Human-computer interaction: changing roles, Oslo, Norway, Oct., 1-8, DOI: 10.1145/1182475.1182476.

[3] Susanne Bødker. 2015. Third-Wave HCI, 10 Years Later-Participation and Sharing. Interactions. ACM, 24-31.

[4] Susanne Bødker. 2016. Rethinking technology on the boundaries of life and work. Personal and Ubiquitous Computing 20, Springer, 533-544.

[5] Emanuel Felipe Duarte and M. Cecilia Calani Baranauskas. 2016. Revisiting the Three HCI Waves: A Preliminary Discussion on Philosophy of Science and Research Paradigms. Proceedings of the 15th Brazilian Symposium on Human Factors in Computing Systems, São Paulo, Brazil, Oct., 1-4, DOI: 10.1145/3033701.3033740.

[6] Philip Agre. 1997. Computation, and human experience. Cambridge; New York: Cambridge University Press.

[7] Paul Dourish. 2001. Where the action is: the foundations of embodied interaction. Cambridge, Mass: MIT Press.

[8] Lucy Suchman. 1987. Plans, and situated actions: the problem of human-machine communication. Cambridge University Press.

[9] Lucy Suchman 2007. Agencies in technology design: feminist reconfigurations. Lancaster University.

[10] Terry Winograd, Ed., Bringing design to software. New York, N.Y.: Reading, Mass: ACM Press; Addison- Wesley, 1996.

[11] Lars-Erik Janlert and Erik Stolterman 2017. Things that keep us busy: the elements of interaction. Cambridge, Massachusetts: The MIT Press.

[12] Christopher Frauenberger. 2019. Entanglement HCI The Next Wave? ACM Trans. Comput. Hum. Interact. TOCHI 27 (1): 1-27.

[13] Umer Farooq and Jonathan Grudin. 2016. Human-computer integration," Interactions 23 (6): 26-32. DOI: 10.1145/3001896.

[14] Florian Floyd Mueller et al. 2020. Next Steps for Human-Computer Integration. Proc. of the 2020 CHI Conference on Human Factors in Computing Systems, Honolulu, HI, USA, 1-15. DOI: 10.1145/3313831.3376242.

[15] Michel Beaudouin-Lafon and Wendy E. Mackay. 2018. Rethinking Interaction: From Instrumental Interaction to Human-Computer Partnerships. Extended Abstracts of the 2018 CHI Conference on Human Factors in Computing Systems, Montreal QC, Canada, 1-5. DOI: 10.1145/3170427.3170635.

[16] Ben Shneiderman, Catherine Plaisant, Maxine Cohen, Steven Jacobs, Niklas Elmqvist, and Nicholaos Diakopoulos. 2016. Grand challenges for HCI researchers. Interactions 23 (5): 24-25. DOI: 10.1145/2977645.

[17] Susanne Bødker and Morten Kyng. 2018. Participatory Design that MattersFacing the Big Issues. ACM Trans. Comput.-Hum. Interact. 25 (1): 4:1-4:31. DOI: $10.1145 / 3152421$.

[18] Liam Bannon, Jeffrey Bardzell, and Susanne Bødker. 2018. Introduction: Reimagining Participatory Design-Emerging Voices. ACM Trans. Comput.-Hum. Interact. 25 , no. 1, p. 1:1-1:8, Feb. 2018, DOI: $10.1145 / 3177794$.

[19] Jeffrey M. Bradshaw, Robert R. Hoffman, David D. Woods, and Matthew Johnson, "The Seven Deadly Myths of 'Autonomous Systems,"' IEEE Intell. Syst. 28, (3): 54-61. DOI: 10.1109/MIS.2013.70.

[20] Rebekka Soma and Jo Herstad. 2018. Turning Away from an Anthropocentric View on Robotics. Envisioning Robots in Society - Power, Politics, and Public Space: Proceedings of Robophilosophy 2018 / TRANSOR 2018, vol. 311, M. Coeckelbergh, J. Loh, and M. Funk, Eds. Wien, Austria: IOS Pres. 53-62.

[21] Rebekka Soma, Vegard Dønnem Søyseth, Magnus Søyland, and Trenton Schulz. 2018. Facilitating Robots at Home: A Framework for Understanding Robot Facilitation," Mar. 2018. 1-6: https://www.thinkmind.org/index.php?view=article\& articleid=achi_2018_1_10_20085.

[22] Johanne Svanes Oskarsen. 2018. Human-supported robot work. Master Thesis, University of Oslo, Department of Informatics, Oslo, Norway.

[23] Diana Saplacan and Jo Herstad. 2019. An Explorative Study on Motion as Feedback: Using Semi-Autonomous Robots in Domestic Settings. Int. J. Adv. Softw. 12 (1 \& 2: 23.

[24] Diana Saplacan, Jo Herstad, Jim Tørresen, and Zada Pajalic. 2020. Division of Work Tasks between Humans and Robots: An Instrumental Analytical Study 
from the Home. Multimodal Technol. Interact. J.

[25] Guri B. Verne. 2020. Adapting to a Robot: Adapting Gardening and the Garden to fit a Robot Lawn Mower. Companion of the 2020 ACM/IEEE International Conference on Human-Robot Interaction, Cambridge, United Kingdom, 34-42. DOI: $10.1145 / 3371382.3380738$.

[26] Suhas Govind Joshi. 2017. Designing for Capabilities: A Phenomenological Approach to the Design of Enabling Technologies for Older Adults. PhD dissertation. University of Oslo, Department of Informatics. https://www.duo.uio.no/handle/ $10852 / 58738$

[27] Suhas Govind Joshi and Tone Bratteteig. 2016. Designing for Prolonged Mastery On involving old people in Participatory Design. Scand. J. Inf. Syst. 28 (1). https //www.duo.uio.no/handle/10852/58736.

[28] Diana Saplacan. 2020. Situated ability: A case from Higher Education on digital learning environments. Lecture Notes in Computer Science, Springer, Ch. 19 vol. HCII 2020, M. Antona and C. Stephanidis, Eds. Springer Nature Switzerland: $1-19$.

[29] Diana Saplacan, Jo Herstad, and Trenton Schulz. Forthcoming. Situated Abilities within Universal Design - A Theoretical Exploration: The Case of The Robotic Wood Table. Int J. Adv. Intell. Syst. 13 (3 \& 4): 14.

[30] Diana Saplacan and Jo Herstad. 2019. Understanding robot motion in domestic settings. Proceedings of the 9th Joint IEEE International Conference on Development and Learning and on Epigenetic Robotics. IEEE XPlore, Oslo. https://ieeexplore.ieee.org/document/8850695

[31] Tone Bratteteig and Guri B. Verne. 2012. Conditions for Autonomy in the Information Society: Disentangling as a public service. Scand. J. Inf. Syst. 24 (2). http://aisel.aisnet.org/sjis/vol24/iss2/3 